H. Н. Дворовенко. Модель ИКТ-компетентности педагога: методология, структурные и содержательные составляющие, критерии оценивания

Научная статья

УДК 37.022, 37.026

DOI: $10.18101 / 2307-3330-2021-1-17-39$

\title{
МОДЕЛЬ ИКТ-КОМПЕТЕНТНОСТИ ПЕДАГОГА: МЕТОДОЛОГИЯ, СТРУКТУРНЫЕ И СОДЕРЖАТЕЛЬНЫЕ СОСТАВЛЯЮЩИЕ, КРИТЕРИИ ОЦЕНИВАНИЯ
}

\author{
(C) Дворовенко Нина Николаевна \\ старший преподаватель, \\ Кузбасский региональный институт повышения квалификации \\ и переподготовки работников образования (КРИПКиПРО) \\ Россия, 650070, г. Кемерово, ул. Тухачевского, 23 \\ nina_dvorovenko@mail.ru
}

Аннотация. В статье рассматривается вопрос о структурных и содержательных составляющих понятия ИКТ-компетентности педагогов, и в их числе понятие компетентности, в аспектах, которые ранее не освещались. Проблематика и развитие вопроса показываются на примерах анализа важнейших для педагогов документов. В составе большого ряда проблем отсутствие информации по основаниям для структурирования, формализации и универсализации требований к ИКТ-компетенциям педагогов, отсутствие рекомендаций по лексическому представлению формулировок компетенций. Выдвигаются конкретные предложения по ряду вопросов, приводится их методологическое обоснование. Предлагаются перечень ключевых ИКТ-компетенций и модель оценивания ИКТ-компетентности педагога в целом.

Ключевые слова: компетентность, ключевые ИКТ-компетенции педагогов, модель ИКТ-компетентности педагога, профессиональный стандарт «Педагог», педагогические технологии, методология

\section{Для цитирования}

Дворовенко Н. Н. Модель ИКТ-компетентности педагога: методология, структура и содержательные составляющие, критерии оценивания // Вестник Бурятского государственного университета. Образование. Личность. Общество. 2021. Вып. 1. С. 17-39.

\section{Введение}

Вопрос о требованиях к компетенциям педагогов в области информационнокоммуникационных технологий (ИКТ) находится в тренде парадигмы высшего образования, обозначаемой понятием «компетентностный подход». Будучи введенным в стандарты образования, этот вопрос затрагивает интересы каждого педагога. Показателем выявляемого в ходе образовательного процесса в системе ИПК состояния проблемы с реальным уровнем ИКТ-компетентности педагогов может служить такой «мелкий» индикатор компетентности в этой области знания и деятельности, как процент умеющих расшифровать, что такое «ИКТ». Уровень конкретных результатов обучения в модуле «ИКТ» педагогов разных специализаций, в частности с использованием дистанционных образовательных технологий, можно видеть в работе [4]. 
Проблематика задачи формирования и развития ИКТ-компетентности учителей широко представлена в научных публикациях. Однако значимость проблемы остается актуальной и сейчас, в период перехода высшего образования на модернизированные образовательные стандарты в виде проектов ФГОС ВО 3+ и 3++. Критическим поводом обращения к этому вопросу в настоящей работе послужило осознание факта отсутствия в опорном рамочном документе «Структура ИКТкомпетентности учителей. Рекомендации ЮНЕСКО» ${ }^{1}$ важнейшей информации о принциииально необходимых ИКТ-компетенциях, которыми должны обладать педагоги. Таких сведений нет и в профессиональном стандарте «Педагог (педагогическая деятельность в сфере дошкольного, начального общего, основного общего, среднего общего образования)» ${ }^{2}$. Здесь в разрядах педагогов различной специализации содержатся лишь разрозненные предложения по требующимся ИКТ-умениям.

В ходе разработки вопроса обозначился большой ряд проблем: 1) отсутствие обоснованных рекомендаций по основаниям для структурирования, формализации и универсализации требований к ИКТ-компетенциям педагогов, в том числе для выделения принципиально необходимых ИКТ-компетенций; 2) отсутствие обоснованной лексической модели составления формулировок ИКТкомпетенций; 3) отсутствие согласия в определениях для связанных понятий из области вопроса о компетентности; 4) отсутствие раскрытого соотношения между профессиональной компетентностью и профпригодностью; 5) при описании ИКТ-компетентности отсутствие сопряжения с параметрами (критериями) компетентности; 6) отсутствие методологического обоснования предложений.

Разрешение этих проблем для задачи настоящей работы позволило предложить перечень ключевых ИКТ-компетенций педагогов и модель ИКТкомпетентности педагога в целом.

Какую информацию дает содержание документа ЮНЕСКО

Обозначая основные аспекты содержания документа с актуальным для задачи настоящей статьи названием «Структура ИКТ-компетентности учителей. Рекомендации ЮНЕСКО» ${ }^{3}$, укажем, что в этом программном документе системно размечено поле профессиональных задач, для решения которых учителям рекомендуется применять функционал средств ИКТ; деятельность учителя при этом ставится на службу развития компетенций учеников. Поле представлено в виде матрицы из 18 ячеек, составленной из шести направлений деятельности педагога

\footnotetext{
${ }^{1}$ Структура ИКТ-компетентности учителей. Рекомендации ЮНЕСКО: Редакция 2.0, 2011. URL: http://iite.unesco.org/pics/publications/ru/files/3214694.pdf (дата обращения: 05.03.2019). Текст: электронный.

${ }^{2}$ Профессиональный стандарт «Педагог (педагогическая деятельность в сфере дошкольного, начального общего, основного общего, среднего общего образования) (воспитатель, учитель)»: утв. приказом Минтруда России от 18.10.2013 г. № 544н (с изм. от 25.12.2014); зарегистр. в Минюсте России 06.12.2013 № 30550. Текст: непосредственный.

${ }^{3}$ Структура ИКТ-компетентности учителей. Рекомендации ЮНЕСКО: Редакция 2.0, 2011. URL: http://iite.unesco.org/pics/publications/ru/files/3214694.pdf (дата обращения: 05.03.2019). Текст: электронный.
} 
H. Н. Дворовенко. Модель ИКТ-компетентности педагога: методология, структурные и содержательные составляющие, критерии оценивания

(6 модулей) и трех уровней сложности педагогической задачи, или, соответственно, трех уровней требующейся компетентности в применении ИКТ, или трех подходов. Названия модулей: Понимание роли ИКТ в образовании; Учебная программа и оценивание; Педагогические практики; Технические и программные средства ИКТ; Организачия и управление образовательным процессом; Профессиональное развитие. Подходы (в колонках): Применение ИКТ; Освоение знаний; Производство знаний. В ячейках в виде типизированных примеров профессиональных ситуаций приводятся описания подходов и фрагменты методик. Вопрос о принципиально необходимых ИКТ-компетенциях в документе не освещен. Матрица является, таким образом, детализированной структурой поля профессиональной деятельности педагога, использующего ИКТ, и речь идет о рекомендаииях по применению ИКТ-умений в структурированной системе областей и ситуаций профессиональной деятельности. При таком содержании документ более правильно именовать: «структура сферы приложения ИКТкомпетентности учителей/педагогов». Представление обобщенной структуры поля такой деятельности педагогов имеет важное самостоятельное значение. Она учитывается и в настоящей работе.

\section{Неоднозначность понятия компетентности}

В настоящее время в научном сообществе нет устоявшейся концепции, что именно должно быть заложено в содержание понятия «ИКТ-компетентность педагога». Такое утверждение относится и к более общему понятию «компетентность», в интерпретацию которого в качестве синонимов закладываются категории знания, умения, навыки, способность, готовность, владение, понимание, личностные качества в различном номинальном составе у разных авторов (примеры $c$ м. [1, с. 33]) и которое в нашей задаче выявления критериев ИКТкомпетентности должно быть определено в первую очередь. Как следствие, оперирование этим понятием, введенным в прагматических целях рейтингового различения специалистов по профессиональным качествам при отборе кадров, а также при аттестации выпускников и соответственно в целях усиления контроля практической направленности обучения, в научно-лексической сфере, как показывает анализ множества научных текстов, сопряжено с ненаучной проблемой неясностей, противоречий и натяжек. Изначально обозначенная необходимость в измерении качества наталкивается на невозможность это сделать, что становится понятным уже при осмыслении предлагаемых дефиниций. Для трактовки понятия «компетентность» используются термины и лексические конструкции неизмеримого содержания - помимо ряда из названных выше «быть способным делать», «быть готовым», «быть в состоянии», «мочь сделать». Как попытки найти компромисс, оставаясь в границах авторитетных определений, нужно рассматривать такие выражения, как «созидательная способность», «подтвержденная готовность», которые не разрешают проблемы.

Более того, это понятие вообще предлагается:

- считать соотносящимся по своему уровню с уровнем таких категорий, как «культура», «красота», которые являются символьными образами, не несущими в себе отнесенности к реально существующим объектам, стоящим за ними, 
в отличие от аналогового образа, и дающими только непрямые указания в их отношении [24];

- воспринимать как «идеологический кодекс» системы образования, идеал выпускника, конкурентоспособного на рынке труда [20, с. 141];

- считать языком - языком компетенций как единым (согласованным) языком для описания академических и профессиональных профилей и уровней высшего образования, а также результатов образования [1, с. 11].

В таком случае исключается условие непосредственной измеримости в принципе. Однако здесь надо сказать, что идея присущности понятию «компетентность» подобных метасвойств порождает новые перспективные смыслы, важные для понимания и интерпретации понятия. Это смысл наличия метауровня в содержании образования как дополнительной «области», заведомо вносимой компетентностным подходом, и смысл не прямого, а опосредованного характера иерархической связи между этим термином и его актуальной дефиницией в описании, который подчеркивает невозможность их прямого соотнесения.

A. Stoff с соавт. [24:], задаваясь вопросом, почему так сложно создавать однозначные для понимания формулировки компетенций, обращают внимание на то, что «под результатом действия понимается нечто видимое, объективное, тогда как компетенция описывает личностные особенности, обеспечивающие достижение результата». Справедливость обоих признаков свидетельствует о присущей этому понятию двойственности характера содержания: «внутреннее внешнее».

Заметим, что значение измеримого содержания в условиях профессиональной деятельности обеспечивает прежде всего формулировка: «уметь делать». Именно к «умениям» сводится трактовка понятия «компетентность» рядом отечественных исследователей. Так, А. М. Новиков называет компетентностный подход «умениевым» подходом, а компетенции считает синонимом умений [10, c. 65]. С. Е. Шишов [23, с. 32] подчеркивает, что только умения поддаются наблюдению, они являются проявлением компетенции. В. А. Демин [7, с. 35] представляет компетентность как «уровень умений личности, отражающий степень соответствия определенной компетенции и позволяющий действовать конструктивно в изменяющихся социальных условиях».

Существенно то, что в формулировке «уметь делать» может быть представлено описание любой деятельности, не только основанной на двигательных действиях, но и интеллектуальной, с подразделением, если нужно, по уровням. При этом надо учитывать, что, как считается, по своему уровню не всякие «умения» могут считаться компетенцией — так, не являются компетенциями умения совершать универсальные учебные действия. Обратим внимание на то, что такие умения-действия, как объяснить, доказать, обосновать, изложить, убедить и мн. др. (см. напр., список глаголов верифицируемых мыслительных действий разного уровня по Блуму [21, с. 32]), конкретизируют способы наблюдаемого в практическом опыте отображения знаний, что актуально и в случае техникотехнологической деятельности. Этот логический переход возвращает к привычному определению компетентного человека как знающего, сведущего в опреде- 
H. Н. Дворовенко. Модель ИКТ-компетентности педагога: методология, структурные и содержательные составляющие, критерии оценивания

ленной области [15, с. 315] и, соответственно, к определению компетентности как обладания знаниями, позволяющими судить о чем-либо, высказывать веское, авторитетное мнение [15, с. 315]. В качестве проявления в действии, направленном вовне, такие знания могут быть оценены с использованием различных средств педагогических или квалификационных измерений.

В контексте признаков «проявление» и «внутреннее - внешнее» нужно отметить возможность конфликта между оценкой личностью своей компетентности и непризнанием ее обществом, что может быть связано как раз с недостаточной развитостью средств проявления профессиональных качеств и непониманием сути компетентности как внешней оценочной характеристики профессиональных качеств. По мнению Л. А. Витвицкой [2], у компетентного специалиста должна быть развита положительная мотивачия к проявлению профессиональных качеств, ибо нельзя «увидеть» непроявленную компетентность. Относительно возможных коллизий конфликта, хотя спорно утверждать, что характеристика «компетентный» для специалиста-профессионала должна включать оценку искусства дипломатии в полемике в недостаточно компетентной, недружественной или агрессивной, но уполномоченной среде, однако является фактом, что умение «защиты» предусматривается уже требованиями к аттестации выпускника. Не может считаться компетентным специалист, не способный защитить свой интеллектуальный продукт. В отношении действий защищающегося психология предусматривает три варианта - бежать, замереть и бороться. Наиболее часто избирается вариант «замереть» с тем, чтобы сориентироваться, но желаемой оценки «компетентный» он не порождает. Вариант «бороться» возможен, когда защищающийся умеет не только выстроить изложение материала в привычной индуктивной логике, но и активно оперировать им на более высоком уровне в технике дедуктивной логики с использованием понятий: «цели», «объект», «предмет», «защищаемые ценности». В связи с актуальностью сказанного способность защиты как личностное качество следует считать необходимой составляющей профессиональной компетентности.

Именно средства личности, обеспечивающие формирование и проявление профессиональной компетентности, как качества специалиста раскрываются в представлениях Дж. Равена-мл. о многокомпонентном характере компетентности [13, с. 75], опирающихся на психофизиологические свойства личности. Термином «компоненты компетентности» Равен (1984) обозначает те характеристики и способности людей, которые позволяют достигать личностно значимых иелей $[12$, с. 280]. Компоненты компетентности рассматриваются как компоненты эффективного поведения, способствующего успешному завершению деятельности. Их перечень в [12, с. 281-297] представлен почти сорока позициями. В [13, с. 84] (1991) этот перечень, приводимый в существенно сокращенном виде в составе таблицы, называемой «картой областей компетентности», подразделяется по «видам компетентности», в основу которых положены «компоненты деятельности» [13, с. 67], на когнитивные, аффективные, волевые с добавлением навыков и опыта. Матрица «карты» имеет 11 колонок, в их названиях отоб- 
ражены три группы профессионально значимых аспектов: Достижения, Сотрудничество, Влияние. Карта представлена в качестве модели компетентности.

Эти представления, безусловно, предусматривались специалистами ЮНЕСКО при разработке модели ИКТ-компетентности. Отличительной чертой моделей в обоих случаях является формат матрищыл. Иной общности, однако, нет.

Нужно отметить, что для оценивания компетентности Дж. Равеном предлагается свой подход («nарадигма» [13, с. 66]), выражающийся в особых методиках измерения [12, с. 10]. В соответствии с ним, принципами адекватного отображения компетентности являются максимальная гетерогенность ключевых признаков [12, с. 10; 13, с. 75-77], их разнообразие и двухэтапность процедуры оценивания компетентности. Сначала выявляются ценности, или «приоритетыз», и только потом оценивается способность сводить воедино различные потенциально важные когнитивные, эмоциональные и волевые усилия ради успешного осуществления деятельности $[13$, с. $67 ; 12$, с. 271]. Важнейшим условием, по его мнению, является осуществление оценивания в ситуации максимального раскрытия способностей (в ситуации личностной значимости — «подходящей для занятия интересной деятельностью») [13, с. 73, 82].

Развитием вопроса оценки профессиональной компетентности выпускника/специалиста можно считать предложение [3] использовать в качестве критериальной характеристики показатель наличия навыков и опыта поведения в ситуациях преодоления трудностей в профессиональной деятельности.

Именно таким подходом, фокусирующим внимание на принщипиально важных проявляющихся профессиональных качествах, имеющих значение для формирования и оценки компетентности выпускника/специалиста, обусловлено выделение нами группы специфических компетентностных профессиональных качеств (далее).

\section{Понятие «компетентность» в настоящей работе}

Развивая этот вопрос в настоящей работе, нужно было прежде всего определить соотношение между понятиями «компетентность» и «квалификация», на необходимость чего указывается в источнике [14]. Компетентность определенно не характеризуется совокупностью знаний и умений, по результатам их измерения в знаниевой парадигме образования определяется и присваивается профессиональная квалификация, что автоматически означает заключение о профпригодности. Понятия компетентности и компетенций отвечают другой парадигме в образовании - компетентностному подходу с идеологией не только прагматизма, результативности, но и личностной ориентации. Соответственно, оценка компетентности должна базироваться на учете иных качеств сверх этого, и ей должна отвечать другая квалификация, причем соотносящаяся с более высоким уровнем содержания образования - метауровнем. Перечень профессионально важных качеств (ПВК), на выявлении которых может основываться оценка компетентности, приведен во втором столбце на схеме рисунок 1. 
Н. Н. Дворовенко. Модель ИКТ-компетентности педагога: методология, структурные и содержательные составляющие, критерии оценивания

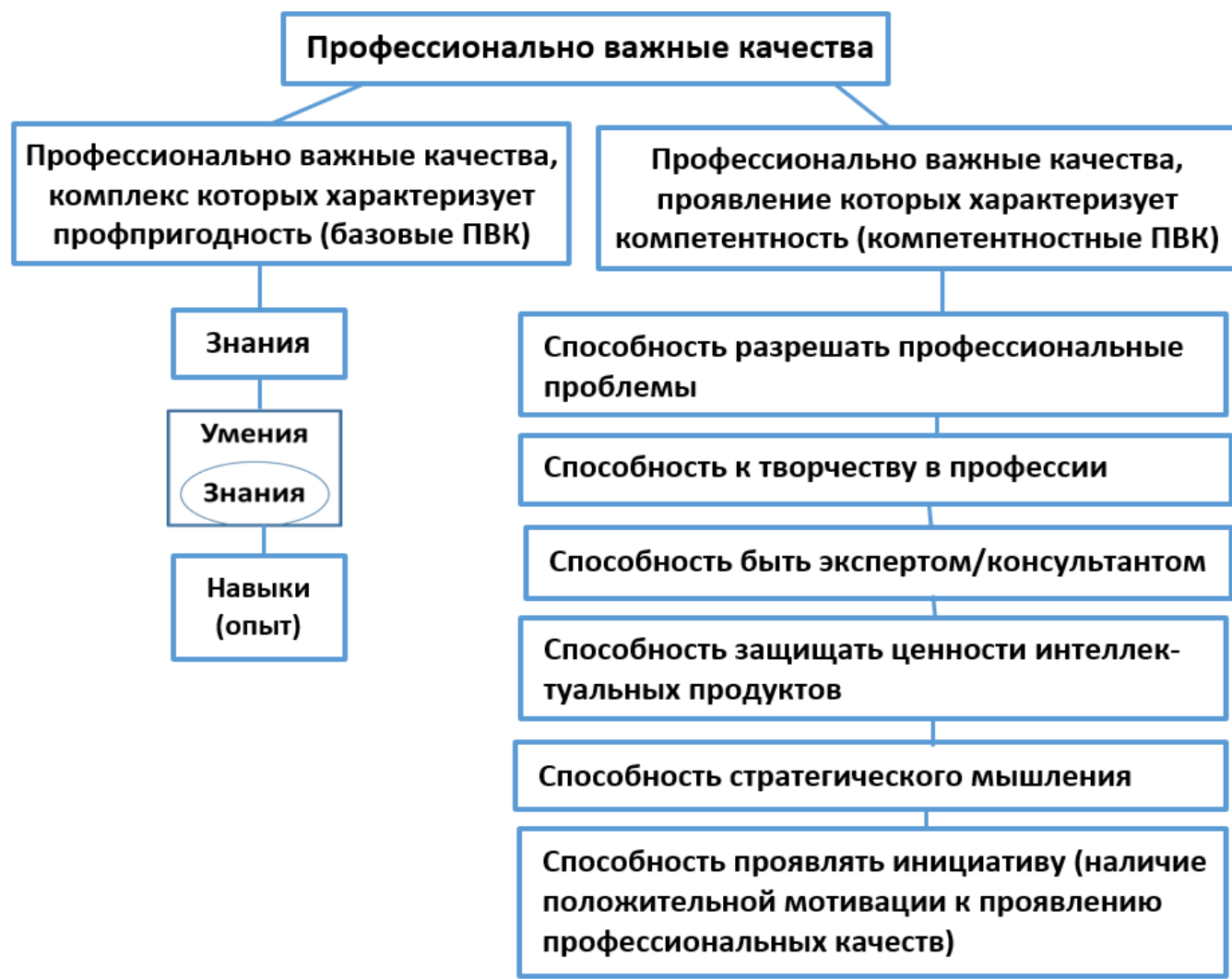

Рис. 1. Структура системы профессионально важных качеств, имеющих значение для оценки профессиональной компетентности и профпригодности как разных подходов

Здесь не только разрывается цепочка «знания - умения - навыки - способности» с выделением «способностей», сами они конкретизированы, и это еще резче разделяет содержание рассматриваемых понятий. Включенные в перечень признаки отличаются ярко выраженным опознавательным характером, они универсальны по формулировкам и заведомо позволяют выявлять наличие именно компетентности в действиях и специалистов-профессионалов, и выпускников, не сводя задачу к определению наличия профпригодности. Они представлены проявляющимися качествами различной природы (когнитивными, аффективными, волевыми, по Дж. Равену). Каждый из шести признаков однозначно характеризует компетентного специалиста. Важно учитывать, что речь не идет о «всеохватной» компетентности специалиста. Конструктивнее говорить о компетентности в определенной области или в определенных вопросах знания/деятельности. При этом возможно предусматривать комплекс задаваемых приоритетных признаков компетентности, состав которых определяется конкретными целями оценивания. Перечисленные качества являются компонентами эффективного поведения. В качестве признаков они наделяются значением критериальных харак- 
теристик (характеристик, заключающих в себе критерии) и, как и базовые ПВК, также подлежат измерению (подтверждению).

Здесь знание - состояние психики (мозга) личности, являющееся результатом того, что информация, воспринятая рецепторами организма или созданная в результате мыслительных операций и действий с ней, стала достоянием памяти личности с возможностью ее извлечения. Продуктом функционирования мозга индивида в этом состоянии являются «знания».

Умение - состояние психики личности, являющееся результатом осознанного освоения иеленаправленного продуктивного действия, выполняемого определенным способом и с определенным качеством [8, с. 146]. Продуктом деятельности индивида в этом состоянии, составляющим достояние памяти, являются «умения».

Способность - свойство («умение») психики индивида, являющееся условием его жизнедеятельности, находить, сохранять в памяти и использовать способы совершения актуальных действий («владеть ими»). «Способности представлены организаиией морфологических структур, приспособленных для выполнения какой-либо деятельности» [19, с. 453]. Особенности психики, характеризующиеся наличием изначально существующих подобных стабильных структур или предрасположенностью к этому, отождествляются с задатками, обусловливающими склонность индивида к успешной реализации определенных действий (видов деятельности). Линейка видов способностей, исходящих из задатков, в направлении усиления этого качества: способность - одаренность талант - гениальность.

Подобные морфологические структуры могут вырабатываться и в результате обучения умениям. Наличие способности к конкретной деятельности, засвидетельствованное из наблюдаемых результатов испытаний или квалифицированных действий индивида, обусловливает его профессиональную характеристику как соответствующего определенной квалификации - в аспекте профпригодности.

Считаем важным обратить внимание на то, что, хотя формулировка ключевого критерия профессиональной компетентности «способность индивида разрешать возникающие проблемы в соответствующей области деятельности» конгруэнтна формулировке собственно способности как «умения» психики находить способы совершения актуальных действий, она описывает способность высокого уровня. В [13, с. 65] приводятся примеры способностей высокого уровня, в их числе способность к познанию и способность проявлять инициативу (лучше компетентную инициативу). Последняя полноправно отображает сущность эффективного и компетентного поведения [12, с. 9, 150; 13, с. 67-68]. По сути, она равнозначна наличию положительной мотивации к проявлению профессиональных качеств (по Витвицкой [2]) и соответственно является профессионально важной характеристикой. Именно природой высокого уровня требующихся способностей определяется сложность функционала профессионально важных качеств, избранных для характеристики компетентности, на схеме рисунка 1. 
H. Н. Дворовенко. Модель ИКТ-компетентности педагога: методология, структурные и содержательные составляющие, критерии оценивания

Такое понимание профессиональной компетентности соответствует представлению об этом понятии как включающем представление о единстве «внутреннего» и «внешнего или выходящего вовне»: это и состояние, и «внутренний» продукт, и наблюдаемый оцениваемый квалификационный результат - качество специалиста в соответствии с критериями и в целом личностная характеристика носителя качества как компетентного, которая в дальнейшем несет смысл его потенциала как гаранта успешности результатов подобных действий и в других ситуациях. Статус (имидж) компетентного порождает доверие к оценкам специалиста (авторитет); доверие к присвоенной высокой профессиональной квалификаиии порождает полномочия.

Относительно еще одного понятия. Компетентность специалиста, по содержанию представляемая диагностированными качествами, безусловно, базируется на обладании оговоренным комплексом профессионально важных качеств, опирающихся на владение необходимым объемом знаний и умений в данной сфере деятельности. Слово «владение», являющееся характерным для сферы образования, служит для обозначения образовательного явления, состоящего в том, что знания и умения (в т. ч. способы действий и навыки) не просто имеются то есть присвоены или выработаны личностью, а активно используются в деятельности в роли средств.

Парадоксально, но приведенные на рисунке 1 компетентностные качества не могут быть заведомо названы компетенциями. Понятие компетенции пока близко не рассматривалось нами, и вот теперь вопрос о месте его в структуре понятия «компетентность» и содержании возник. Встала проблема объяснения того, как в процессе формирования профессиональной компетентности происходит превращение базовых ПВК, характеризующих профпригодность, в перечисленные сугубо компетентностные качества.

При учете всех обстоятельств ситуации стало ясно, что структура группы компетентностных ПВК помимо явно выраженных специфических компетентностных качеств должна включать в качестве переходной в схеме на рис. 1 подгруппу базовых компетентностных качеств, которые и должны интерпретироваться как собственно компетенции со всеми вытекающими последствиями. При этом необходимо принять, что в случае понятия компетенции ее единственные компоненты «знания» и «умения» отличаются особым характером. Вопервых, нацеленностью на реализацию и реализуемостью в продуктивной профессиональной деятельности. Во-вторых, наличием в их содержании компонентов «высокого уровня», что связано с возрастанием значимости универсального, обобщенного знания относительно уровня профпригодности, и это должно быть отражено в их формулировках. В-третьих, и главное, уверенным и успешным «владением» этими знаниями и умениями. То есть компонент «навыки и опыт», являющийся «рядовой» составляющей группы базовых ПВК, в группе базовых компетентностных качеств становится ключевым условием принадлежности в виде условия «владение».

Так как знания и умения, рассматриваемые вне компетентностного подхода к формированию и оценке результатов образования, заведомо не имеют «выхода» 
на компетентность и не могут соотноситься с компетенциями, нужно осознавать факт принятия этого подхода. В таком случае обладание конкретными компетенциями (как ценностью и потенциальным личностным «товаром») означает (и гарантирует): 1) владение соответствующими знаниями и умениями «высокого уровня», 2) выполнение профессиональных действий на адекватном базовом компетентностном уровне и 3) наличие способности оценить компетентный характер действий другого человека, в том числе смысл и значение его сnецифических компетентностных качеств, не обладая ими (благодаря знанию сути и терминологии компетентностного подхода).

Чтобы ответить на вопрос, в каком отношении находятся описываемые так базовые компетентностные качества (компетенции) и специфические компетентностные качества, нужно учесть, что компетенции, в отличие от последних, являющихся непосредственными компонентами профессиональной компетентности, не составляют характеристического содержания профессиональной компетентности. В этих целях потребуется превращение теперь уже базовых компетентностных качеств в специфические компетентностные качества. Это осуществляется посредством преобразующего личностного качества, конкретно - способности сводить воедино различные потенциально важные когнитивные, эмоциональные и волевые усилия ради успешного осуществления деятельности (по Дж. Равену). Рождение такой способности означает становление профессиональной компетентности. Ее содержание по своей сути близко к описанию механизма творческого начала в профессии.

Таким образом, результаты профессионального образования, отвечающие метауровню содержания образования в условиях действия компетентностного подхода, обеспечиваются двумя уровнями формируемой профессиональной компетентности: уровнем специфических компетентностных качеств, составляющим характеристическое содержание компетентности, и его подуровнем - базовым уровнем компетенций с его описанной выше ролью и потенциальными возможностями. Сказанное согласуется с моделью Равена двухэтапной оценки компетентности. Соответственно, при описании компонентов актуальной профессиональной деятельности с позиции оценки компетентности необходимо указывать не только отвечающие им собственно компетентностные качества как ключевые признаки, но и поддерживающие эти качества компетенции, осознавая, что компетенции - это залог компетентности, достигаемой в результате больших усилий и большого опыта.

Компетентность понимается как внешняя оценочная характеристика качества профессиональной деятельности, даваемая неофициально или в результате организации действий официальной процедуры по следующему алгоритму.

1. Сформировать для конкретной программы продуктивной деятельности два перечня профессионально важных качеств выпускника/специалиста для возможности с их помощью оценивать профессиональную компетентность (не профпригодность) по уровням, а именно перечень специфических компетентностных качеств и перечень профессионально важных компетенций, допуская выделение приоритетных характеристик. Указать, наработка каких компетенций 
Н. Н. Дворовенко. Модель ИКТ-компетентности педагога: методология, структурные и содержательные составляющие, критерии оценивания

требуется для формирования конкретных специфических компетентностных качеств.

2. Подобрать способы (средства) измерения критериальных характеристик отдельно для специфических компетентностных качеств и компетенций, обозначив измеряемые показатели.

3. Выполнить измерения.

4. Оценить результаты измерений критериальных показателей по квалификационным шкалам компетенций и специфических компетентностных качеств.

5. Составить умозаключение о мере (степени) компетентности выпускника/специалиста в данной профессиональной области (в т. ч. о том, какими уровнями представлено содержание компетентности).

6. Вынести решение.

Методология оценивания компетентности здесь является смешанной - основанной на педагогических/квалификационных измерениях и экспертных суждениях, как рекомендовано, например, в [17]. В настоящей работе исследования и предложения направлены на преодоление в методологии оценивания компетентности ряда вопросов известной проблемы: «эффективность работы по оцениванию качества учебных достижений зависит от того, насколько операционализированы показатели качества, представлены в виде стандартов, критериев и показателей, поддающихся измерению или экспертному заключению» [17].

Термин «компетентность» имеет собирательное значение и для оценки характера деятельности специалиста используется только в единственном числе.

Вопрос конструирования формулы описания компетенций рассматривается ниже.

В обновленных стандартах высшего образования третьего поколения (ФГОС $3+)$ для педагогических специальностей компетентность выпускников представлена лишь совокупностью компетениий - профессиональных, общепрофессиональных и общекультурных. Вопрос владения педагогами-выпускниками информационными технологиями, методами управления информацией, методами работы с компьютером на пользовательском уровне отнесен к области общекультурных компетениий.

\section{Сложности при формулировании компетенций}

Считается, что вопрос о мере компетентности специалиста должен решаться в контексте конкретной отрасли или даже организации в связи с особенностями содержания трудовой деятельности. Диагностика компетентности процессуально может осуществляться по специальным методикам с оценкой результатов соответствующих квалификационных измерений по шкале компетентности. При этом вынесение заключения о наличии профессиональной компетентности должно сопровождаться указанием средств удостоверения такой специфической способности в профессиональной деятельности. Между тем в литературе отсутствуют рекомендации относительно лексического аппарата для описания диагностированных качеств в аспекте оценки компетентности и компетенций, и в каждом конкретном случае вопрос представления и сопровождения этих терминов, принципиально важных для образования, решается по-своему. Так, в [1, с. 43] 
демонстрируются многочисленные примеры, однако к описаниям компетенций, представляемым обобщенно-образными определениями - согласованными и несогласованными, в кавычках и без, имеются претензии, как и к варианту «компетенция в области ...», прежде всего из-за того, что для понимания необходимы расшифровка или конкретизация содержания, то есть указание характеристик, подлежащих измерению, и специфических компетентностных качеств, на формирование которых направлены компетенции. Трудности в составлении описания этих понятий иногда авторами скрываются за табличной формой представления материала, иногда авторы просто уклоняются от явного употребления этих терминов.

Такая проблема проявляется в текстах профессиональных стандартов «Педагог» ${ }^{1}$ и «Педагог дополнительного образования детей и взрослых» ${ }^{2}$, интересующих нас в связи с вопросом об ИКТ-компетенциях педагогов. Возможно, здесь имеет место спорная ситуация с приятием собственно компетентностного подхода, как в [14], но факт, что самих слов «компетентность» или «компетенция» здесь практически нет. В качестве подконтрольных категорий предусматриваются «трудовые действия», «необходимые умения» и «необходимые знания». В стандарте ${ }^{3}$ с теми же параметрами-показателями слово «компетентность» встречается в двух местах, в том числе в разделе целей в виде выражения «формирование компетентностей и умений», при этом значения понятий не уточняются. В тексте Рекомендащий от ЮНЕСКО в содержимом столбца с названием «Способность...» присутствуют вперемешку формулировки, выстраиваемые через «умения» и «способности», без прояснения в глоссарии связи или различия в толковании этих понятий. Заголовок столбца с требованиями к компетенциям учителя прописан просто в виде слов «Педагоги должны (быть знакомы с ..., уметь рассказать на профессиональном языке, отлично знать)».

Идеальным решением было бы включить в одну конструкцию слово «компетенция» и ее дескриптор («описыватель»), содержащий информацию 1) о характере иерархического соотношения «компетенции» и ее актуальной дефиниции, 2) о критериальной характеристике, подлежащей контролю или измерению (владение конкретным знанием или умением «высокого уровня»), 3) о содержании этих знаний или умений и 4) о том, в контексте какого компонента деятельности

${ }^{1}$ Профессиональный стандарт "Педагог (педагогическая деятельность в сфере дошкольного, начального общего, основного общего, среднего общего образования) (воспитатель, учитель)": утв. приказом Минтруда России от 18.10.2013 г. № 544н (с изм. от 25.12.2014); зарегистр. в Минюсте России 06.12.2013 № 30550. Текст: непосредственный.

${ }^{2}$ Профессиональный стандарт «Педагог дополнительного образования детей и взрослых»: утв. Приказом Минтруда России от 08.09.2015 г. № 613н; зарегистр. в Минюсте России 24.09.2015 г. № 38994. Текст: непосредственный.

${ }^{3}$ Там же.

${ }^{4}$ Структура ИКТ-компетентности учителей. Рекомендации ЮНЕСКО: Редакция 2.0, 2011. URL: http://iite.unesco.org/pics/publications/ru/files/3214694.pdf (дата обращения: 05.03.2019). Текст: электронный. 
Н. Н. Дворовенко. Модель ИКТ-компетентности педагога: методология, структурные и содержательные составляющие, критерии оценивания

и какого специфического компетентностного качества рассматривается компетенция.

Назовем для сравнения и отбора примеры начала некоторых таких формулировок с иерархичным представлением критериальной характеристики:

- «компетенция умения... или знания ...»

- «компетенция владения умением... или знанием ...»

- «компетенция, состоящая во владении умением... или знанием ...»

- «компетенция, соответствующая владению умением... или знанием ...» (или диагностируемая по владению умением... или знанием ...»).

В настоящей работе считаются приемлемыми для употребления в текстах все случаи, кроме первого, в связи с отсутствием в нем ключевого для определения компетенции слова «владение». Везде должно подразумеваться, что «умение ...» (или «знание ...») - не компетенция. Владение умениями или знаниями, причем высокого уровня, - вот критериальная характеристика, принятая здесь для организации измерения/диагностики конкретного профессионально важного качества, которым условно характеризуется соответствующая компетенция. В третьем случае по сравнению со вторым пространственное разделение (опосредование) «компетенций» и «умений» в конструкции усилено за счет введения своего рода коннектора. В четвертом случае смысловое дистанцирование еще больше.

К вопросу о формулировках подчеркнем необходимость понимания того, что показатели критериальных характеристик измеряются (хоть и сложным образом), тогда как в отношении компетенций и компетентности индивида на основании результатов измерений после сопоставления с критериями в процессе $\partial u a-$ гностики [9] делается умозаключение и выносится решение - см. выше.

Рабочие примеры формулировок компетенций можно видеть далее.

Ключевые ИКТ-компетенции педагогов

Уверенность в адекватном перечислении и представлении ИКТ-компетенций нередко, причем ошибочно, учителями связывается с профессиональным стандартом «Педагог». Для иллюстрации действительной ситуации с ИКТкомпетенциями в этом документе напомним, что структура стандарта имеет два раздела ( $A$ и $B)$, названия которых начинаются со слов «Обобщенная трудовая функция». Один раздел посвящен проектированию и реализации образовательного процесса, другой - проектированию и реализации основных общеобразовательных программ. Образовательному процессу поставлены в соответствие обучение, воспитание и развитие (как трудовые функции), основным общеобразовательным программам - 1) дошкольное, 2) начальное, 3) основное и среднее образование. Кроме того, в разделе реализации программ присутствуют: 4) модуль «Предметное обучение. Математика» и 5) модуль «Предметное обучение. Русский язык». Таким образом, в стандарте «Педагог» представлено восемь «трудовых функций». Для каждой из них информация размещается под тремя названными ранее рубриками: трудовые действия, необходимые умения и необ- 
ходимые знания. В составе стандарта «Педагог дополнительного образования детей и взрослых» ${ }^{1}$ три раздела и одиннадцать трудовых функций.

Так как разработчики стандарта «Педагог» в конечной версии документа отказались от идеи, заложенной в его опубликованном и обсуждавшемся проекте, привести перечень ИКТ-компетенций в отдельном приложении, ИКТкомпетенции приводятся в обоих стандартах вперемешку с педагогическими профессиональными компетенциями в разделах соответствующих трудовых функций, причем в произвольных формулировках. В связи с задачей их анализа потребовалось выбирать их из общего списка, ориентируясь на наличие упоминаний об ИКТ или об информационно-образовательной среде и на предположение о возможности эффективно осуществлять конкретный компонент профессиональной деятельности с помощью ИКТ. Выделенные нами таким образом 14 позиций перечислены в [5]. В [16] приводятся 18 позиций, выделенных Б. Е. Стариченко. Расхождение наглядно свидетельствует о разнобое в формулировках, осложняющем их интерпретацию. Аналогичное исследование выборок из стандарта «Педагог дополнительного образования» не дало существенного результата в связи с их скудностью; отметим факт отсутствия в тексте стандарта актуального для образования понятия современной информационнообразовательной среды (ИОС).

Анализ выборки показал следующее. Формулировки, касающиеся использования средств ИКТ, представлены только для пяти видов трудовых функций из восьми (их нет для Воспитания и Развития, а также для Начальной школь). ИКТ упоминаются только в составе трудовых действий и необходимых умений, их формулировки отражают крайне обобщенные понятия либо элементарные действия. В пунктах выборки присутствуют элементы одинакового содержания, описываемого разными словами. Все связанные с ИКТ формулировки относятся непосредственно к организации образовательного процесса (нет относящихся к области профессионального развития).

Для выявления принципиально необходимых ИКТ-компетенций потребовались интерпретация, систематизащия и обобщение выделенного списка формулировок. В связи с важностью «умений» в рассматриваемой техникотехнологической области деятельности педагогов (ИКТ) позиции списка для начала были переформулированы единообразно через умения. Демонстрация качества формулировок и трудностей, возникавших при их обработке, может быть проведена на примере совместной интерпретации следующих фрагментов текстов:

1) умение «формирования ... информационной образовательной среды, ... реализующей принципы современной педагогики»;

2) умение «применять современные образовательные технологии, включая информационные»;

\footnotetext{
${ }^{1}$ Профессиональный стандарт «Педагог дополнительного образования детей и взрослых»: утв. Приказом Минтруда России от 08.09.2015 г. № 613н; зарегистр. в Минюсте России 24.09.2015 г. № 38994. Текст: непосредственный.
} 
H. Н. Дворовенко. Модель ИКТ-компетентности педагога: методология, структурные и содержательные составляющие, критерии оценивания

3) умение «использовать современные способы оценивания»;

4) умение «формирования установки обучающихся на коммуникацию в максимально широком контексте, в том числе в гипермедиаформате».

Содержание первых трех позиций обобщенно можно представить смыслом компетенции, состоящей во владении умением реализовать в профессиональной деятельности (в образовательном процессе) педагогические технологии, опираюшиеся на ИК-технологии. Интерпретация четвертой формулировки потребовала особого анализа. Подобная коммуникация может реализоваться в современных электронных средах, основанных на принципах Веб 2.0, причем в разнообразных известных форматах. Такие форматы успешно проявили себя в области образования, они представлены в интернете множеством веб-приложений, и в частности сервисами Google. Использование их в образовании является востребованным, так как это позволяет организовывать, как пример, совместную продуктивную сетевую деятельность (в том числе в виде проектов), выполняя задачи как раз воспитания и развития обучающихся. Для педагога подобрать оптимальную сетевую среду, спроектировать сценарий продуктивной коммуникации обучающихся, избрав для нее соответствующий технологический (медиа), а также педагогический дизайн, и организовать деятельность по созданию продукта означает владение умением разработать и реализовать опять-таки педагогическую технологию, опирающуюся на использование ИКТ. В такой интерпретации коммуникаиия в гипермедиаформате оказывается содержанием одной из общеизвестных инновационных педагогических технологий.

Становится понятной причина, по которой формулировки ИКТ-компетенций в утвержденной версии стандарта «Педагог» оказались возвращенными из приложения на исходные места, в разделы соответствующих трудовых функций: не был найден принцип их обобщения (подход).

Изложенным путем список из 14 выявленных формулировок как исходный рабочий материал из стандарта «Педагог» был преобразован в перечень действительно ИКТ-компетенций.

1. Компетенция владения умением эффективной работы с основными средствами ИКТ (оборудование, программы), включая продуктивную коммуникацию в сетевых средах, как с технико-технологическими средствами деятельности в современной информационно-образовательной среде.

2. Компетенция владения умением обеспечить профессиональную деятельность информационно-методическими средствами организачии деятельности (интернет-информацией, коллекциями электронных образовательных ресурсов в составе создаваемой ресурсно-информационной базы), что включает знание местонахождения в Сети и умения поиска, извлечения и технологического использования, составления библиографической записи и оценки.

3. Компетенция владения умением эффективной организации образовательного процесса, основанного на использовании ИКТ (и в частности коммуникации в сетевых средах в целях учебного общения и сотрудничества), что включает умения выбора адекватных методов, форм деятельности и средств ИКТ в со- 
ставе проектируемой педагогической технологии, а также умения интеграции в ней ИКТ и современных педагогических технологий.

Деятельность педагогов по профессиональному развитию, в том числе научно-исследовательская и научно-методическая деятельность, отнесена к последнему пункту в качестве ориентированной на совершенствование образовательного процесса.

Каждая из формулировок ИКТ-компетенций перечня имеет обобщенный характер и включает большое число детализированных ИКТ-компетенций как отображение сложных конкретных умений и знаний. Дифференциация компетенций опирается на базовые основания педагогики в виде методов, средств и форм организации деятельности обучающихся в составе реализуемой (разрабатываемой) учителем/педагогом педагогической технологии. Это обстоятельство дает основание считать их базовыми, принципиально необходимыми, - иначе говоря, ключевыми ИКТ-компетенциями, которыми должны обладать педагоги.

Этим перечнем задаются актуальные направления развития ИКТкомпетенций в составе личной программы педагога. Названный простой состав первоочередной программы персонального ИКТ-развития педагогам легко запомнить.

Формулировки позиций перечня в качестве базовых требований к компетенциям являются универсальными для педагогов разных специализаций как в профессиональном аспекте, так и в аспекте ИКТ, что видится небесполезным в перспективе перехода на образовательные стандарты ФГОС ВО четвертого поколения [11] для укрупненных групn специальностей и направлений подготовки.

Именно эти направления развития ИКТ-компетенций должны определять базовую программу подготовки учителей/педагогов в системе ИПК на настоящем этапе информатизации высшего педагогического образования.

Выявление ключевых ИКТ-компетенций помогло спроектировать список актуальных компонентов продуктивной деятельности педагогов с использованием средств ИКТ, имеющих значение для оценки ИКТ-компетентности.

\section{О подходах к систематизации ИКТ-компетенций}

Прослеживая вопрос возможной переклички выдвинутых положений со структурой и содержанием понятия «ИКТ-компетентность педагога» в рассматриваемых в настоящей работе документах, укажем, что Б. Е. Стариченко [16] при анализе своего списка ИКТ-компетенций, выведенного из стандарта «Педагог», предлагает иной принцип их систематизации: он выделяет две составляющие технологическую и методическую; они охарактеризованы как уровни.

А. Ю. Уваров (являвшийся одним из консультантов при подготовке рекомендаций ЮНЕСКО и участником перевода на русский язык) в своем документе [18, c. 15] с комментариями к Рекомендациям от ЮНЕСКО разъясняет, что в содержание ИКТ-компетентности разработчиками «заложены... частнометодические и общедидактические составляющие подготовки учителя. Само использование ИКТ включено в систему педагогических методов, и от учителя здесь требуется не только знание современных педагогических технологий, но и умение их реально применять в своей учебной работе в классе на основе возможностей, 
H. Н. Дворовенко. Модель ИКТ-компетентности педагога: методология, структурные и содержательные составляющие, критерии оценивания

предоставляемых средствами ИКТ». В частности, автором приводится перечень видов и направлений профессиональной деятельности, в которых могут быть использованы возможности сетевых сред [18, с. 19]. Соглашаясь с формулировками роли и места умений и знаний и педагогических технологий в содержании понятия ИКТ-компетентности, которые отражают скорее собственные конструктивные представления автора, отметим, что систематизация требующихся (необходимых) ИКТ-компетенций по какому-либо основанию в документе [18] тоже не представлена. Понятие «педагогическая технология» в тексте самих рекомендаций от ЮНЕСКО не применяется.

Предложенный (выведенный) нами перечень ключевых ИКТ-компетенций педагогов по своему содержанию, как оказалось, фактически совпадает с обозначенным в стандартах для общей школье, в частности во ФГОС ООО, составом ИОС образовательной организации. Так, согласно ${ }^{1}$ «информационно-образовательная среда образовательного учреждения включает:

- комплекс информационных образовательных ресурсов, в том числе цифровые образовательные ресурсы,

- совокупность технологических средств информационных и коммуникационных технологий: компьютеры, иное ИКТ-оборудование, коммуникационные каналы,

- систему современных педагогических технологий, обеспечивающих обучение в современной информационно-образовательной среде».

Причина совпадения содержания списков разного происхождения (число пунктов не имеет значения) кроется в том, что в обеих ситуациях рассматривается один объект и, главное, один предмет. Объектом является педагогическая система с ее составом [10, с. 167] в современной информационно-образовательной среде. Предметом является педагогическая технология образовательного процесса, основанного на использовании ИКТ как результат проектирования и реализации его деталей в рамках педагогической системы и (напр., [10, с. 180]) как система условий, форм, методов, средств и критериев решения поставленной педагогической задачи; под каждую педагогическую задачу учителем выстраивается конкретная педагогическая технология [10, с. 183]. Переход от условий традиционного обучения к условиям ИКТ-насыщенной образовательной среды повлек принципиальные изменения именно в средствах, методах и формах организации деятельности обучающихся в составе уже не просто модернизированной, а принципиально новой педагогической технологии. Именно подход, в основе которого лежит задача соответствующего обеспечения образовательного процесса, причем в соответствии с базовыми основаниями педагогики, обусловил указанный набор средств в составе структуры современной ИОС, обслужсивающей образовательный прочесс. Аналогичным образом любой неупорядоченный список значимых ИКТ-умений (или, иерархически выше, ИКТ-компетенций) учителей при

\footnotetext{
${ }^{1}$ Федеральный государственный образовательный стандарт основного общего образования: утв. приказом Мин. образования и науки РФ от 17 декабря 2010 г. № 1897. Текст: непосредственный.
} 
его анализе профессиональными педагогами как средств в составе условий, способствующих решению педагогических задач, должен будет оказаться систематизированным по тем же основаниям.

Необходимо отметить, что в тексте стандарта «Педагог» список требующихся «ИКТ-компетентностей» уже приведен (в разделе трудовой функции «обучение»), причем он оказался популярным в качестве закрывающего проблему. Так, согласно ${ }^{1}$, педагог должен «владеть ИКТ-компетентностями:

- общепользовательская ИКТ-компетентность;

- общепедагогическая ИКТ-компетентность;

- предметно-педагогическая ИКТ-компетентность (отражающая профессиональную ИКТ-компетентность в соответствующей области человеческой деятельности)».

Использованный в² подход к систематизации считаем неудачным как минимум по трем причинам.

1) формулировки составлены некорректно: слово «компетентность» наделяется одновременно двумя определениями альтернативного смысла, что вызывает замешательство, - например, «общепедагогическая» и «ИК-технологическая», «профессиональная» и «ИК-технологическая» и т. п.;

2) используемая терминология («общепользовательская», «общепедагогическая», «предметно-педагогическая» ИКТ-компетентность) нуждается в пояснении смысла (позиции не расшифрованы);

3) дифференциация позиций не опирается на базовые педагогические основания и потому не является научно обоснованной.

Инциденты, отмеченные здесь и в других местах настоящей статьи, свидетельствуют о необходимости пересмотра стандарта «Педагог», а также «Педагог дополнительного образования детей и взрослых», причем не только ради оптимального представления формулировок требующихся от педагогов компетенций в области ИКТ. Нужно признать, что в этих документах не раскрыта ориентация на современные парадигмы образования и, в частности, на компетентностный подход, что прискорбно в связи с предстоящим сопряжением профессиональных стандартов со стандартами ФГОС ВО в их актуализированный формат 3++ [11].

Характеристика ИКТ-компетентности педагога

Обобщение представлений, полученных в ходе исследования, позволяет выдвинуть модель способа отображения и оценки эффективного поведения педагога в аспекте компетентного использования информационнокоммуникационных технологий в конкретных вопросах профессиональной деятельности - в рамках идеологии наличия мета-уровня в содержании образования, вносимого компетентностным подходом. Модель оценивания ИКТ-

\footnotetext{
${ }^{1}$ Профессиональный стандарт «Педагог (педагогическая деятельность в сфере дошкольного, начального общего, основного общего, среднего общего образования) (воспитатель, учитель)»: утв. приказом Минтруда России от 18.10.2013 г. № 544н (с изм. от 25.12.2014); зарегистр. в Минюсте России 06.12.2013 № 30550. Текст: непосредственный.

2 Там же.
} 
H. Н. Дворовенко. Модель ИКТ-компетентности педагога: методология, структурные и содержательные составляющие, критерии оценивания

компетентности педагога представлена в таблице 1 в виде матрицы, в которой отражена также методология организации этой процедуры.

Матрица полноценно предоставляет формат, чтобы зафиксировать результаты диагностики имеющихся ИКТ-компетенций и специфических компетентностных качеств педагога в пространстве профессиональной деятельности с использованием ИКТ-средств и вынести решение о мере его ИКТ-компетентности. Каждый компонент актуальной деятельности соотнесен со специфическими признаками компетентности, причем в этой графе присутствуют все шесть компетентностных признаков из рисунка 1. Формулировки компонентов продуктивной профессиональной деятельности и критериев (признаков) имеют универсальный характер - они безотносительны к специализации педагога. Конкретизация закладывается в формулировки выявленных компетенций и в указание выявленных специфических признаков. Заметим, что такой компонент профессиональной деятельности, как саморазвитие в области ИКТ, не включен в таблицу на том основании, что он не отвечает условию внешней направленности деятельности. Конкретизация способов шкалирования оценок и формулировок выносимых решений здесь не предусмотрена, это область практического применения модели.

Таблица 1

Модель оценивания ИКТ-компетентности педагога

\begin{tabular}{|c|c|c|c|}
\hline \multirow{3}{*}{ № } & \multirow{3}{*}{$\begin{array}{l}\text { Компоненты профессиональной деятельно- } \\
\text { сти с использованием средств ИКТ }\end{array}$} & \multicolumn{2}{|c|}{$\begin{array}{l}\text { Критерии, подтверждающие } \\
\text { ИКТ-компетентность на уровнях }\end{array}$} \\
\hline & & $\begin{array}{l}\text { Уровень базовых ком- } \\
\text { петентностных ка- } \\
\text { честв (компетенций) }\end{array}$ & $\begin{array}{l}\text { Уровень спе- } \\
\text { цифических } \\
\text { компетент- } \\
\text { ностных ка- } \\
\text { честв }\end{array}$ \\
\hline & & $\begin{array}{l}\text { Признаки (владение } \\
\text { конкретными знания- } \\
\text { ми и умениями «высо- } \\
\text { кого уровня») }\end{array}$ & $\begin{array}{l}\text { Признаки } \\
\text { (Указать) }\end{array}$ \\
\hline 1 & $\begin{array}{l}\text { Владение различными, и в первую очередь } \\
\text { основными, средствами ИКТ (оборудование, } \\
\text { программы), включая сетевые среды, в про- } \\
\text { фессиональной деятельности }\end{array}$ & (Назвать) & $\begin{array}{l}\text { Эксперт/ кон- } \\
\text { сультант. } \\
\text { Способность } \\
\text { разрешать } \\
\text { проблемы }\end{array}$ \\
\hline 2 & $\begin{array}{l}\text { Обеспечение профессиональной деятельно- } \\
\text { сти информационно-методическими сред- } \\
\text { ствами организации деятельности (создание } \\
\text { собственной } \\
\text { базы) }\end{array}$ & (Назвать) & $\begin{array}{l}\text { Эксперт/ кон- } \\
\text { сультант. } \\
\text { Способность } \\
\text { разрешать } \\
\text { проблемы }\end{array}$ \\
\hline 3 & $\begin{array}{l}\text { Организация на практике эффективного об- } \\
\text { разовательного процесса, основанного на }\end{array}$ & (Назвать) & $\begin{array}{l}\text { Способность } \\
\text { разрешать }\end{array}$ \\
\hline
\end{tabular}




\begin{tabular}{|c|c|c|c|}
\hline & $\begin{array}{l}\text { использовании ИКТ и осуществляющегося } \\
\text { посредством специально разрабатываемой } \\
\text { педагогической технологии }\end{array}$ & & $\begin{array}{l}\text { проблемы. } \\
\text { Эксперт/ кон- } \\
\text { сультант }\end{array}$ \\
\hline 4 & $\begin{array}{l}\text { Эффективное использование ИК-технологий } \\
\text { в различных сферах практической професси- } \\
\text { ональной деятельности (ориентация на мат- } \\
\text { рицу от ЮНЕСКО) }\end{array}$ & (Назвать) & $\begin{array}{l}\text { Проявление } \\
\text { инициативы. } \\
\text { Творчество в } \\
\text { профессии }\end{array}$ \\
\hline 5 & $\begin{array}{l}\text { Презентация (отображение) ценностей опыта } \\
\text { собственного методологического ИК- } \\
\text { технологического подхода к организации } \\
\text { образовательного процесса на научно- } \\
\text { информационных площадках профессио- } \\
\text { нальной среды (площадках обмена опытом) }\end{array}$ & (Назвать) & $\begin{array}{l}\text { Проявление } \\
\text { инициативы. } \\
\text { Творчество в } \\
\text { профессии. } \\
\text { Способность } \\
\text { защищать } \\
\text { интеллект. } \\
\text { ценности. } \\
\text { Стратегич. } \\
\text { мышление }\end{array}$ \\
\hline 6 & $\begin{array}{l}\text { Владение проблематикой вопроса об ИКТ- } \\
\text { компетентности на понятийном и термино- } \\
\text { логическом уровнях (в т. ч. владение согла- } \\
\text { сованными представлениями о структуре и } \\
\text { содержании понятий «ИКТ-компетентность } \\
\text { педагога» и «компетентность» и о составе } \\
\text { принципиально необходимых } \\
\text { компетенций педагога) } \\
\end{array}$ & (Назвать) & $\begin{array}{l}\text { Эксперт/ кон- } \\
\text { сультант. } \\
\text { Способность } \\
\text { разрешать } \\
\text { проблемы }\end{array}$ \\
\hline \multicolumn{4}{|c|}{$\begin{array}{l}\text { Метаданные о характере ИКТ-компетентности } \\
\text { Вид ИКТ-компетентности: являются ИКТ главным предметом/содержанием профессио- } \\
\text { нальной педагогической деятельности или не являются; соответственно, ИКТ- } \\
\text { компетентность имеет профессиональный или общекультурный характер }\end{array}$} \\
\hline & $\begin{array}{lll}\text { Нка } & \text { ИКТ-компетентности } \\
\text { пользованием шкал }\end{array}$ & $\begin{array}{l}\text { (В соотв. с избранной } \\
\text { формулировкой) }\end{array}$ & $\begin{array}{l}\text { (В соотв. с } \\
\text { избранной } \\
\text { формулиров- } \\
\text { кой) }\end{array}$ \\
\hline
\end{tabular}

\section{Заключение}

В изложенной кониепиии ИКТ-компетентности педагога интегрированы конструктивные подходы и воззрения исследователей-предшественников. Все аспекты решения вопроса рассматриваются через призму методологических оснований. Показанные подходы раскрывают принципы упорядочения большой области связанных понятий. Модель является результатом проекиии выработанных в работе представлений о понятиях компетентности и компетенций, как соотносящихся с метауровнем современного содержания образования, на область ИКТ-деятельности педагогов. Эти представления согласуются с представлениями исследователей-психологов, активно рассматривающих вопрос о метауровне в содержании образования в контексте компетентностного подхода и раскрывающих его в аспекте повышения качества образования через такие понятия, как 
Н. Н. Дворовенко. Модель ИКТ-компетентности педагога: методология, структурные и содержательные составляющие, критерии оценивания

метакогнитивные компоненты, навыки, способности, процессы, стратегии и др. (см., в частности, работы А. В. Карпова, А. А. Карпова, О. Е. Антипенко). Педагогам предоставляется возможность провести ревизию понимания статуса своего наличного ИКТ-багажа в терминах компетентностного подхода.

Ценности содержания ключевых ИКТ-компетенщий лежат в области основ педагогической деятельности. Они отражают направленность учителя на создание оптимальной педагогической технологии, основанной на использовании ИКТ, как средства деятельности педагога, стремящегося за счет применения ИКТ повысить эффективность своей деятельности.

В настоящее время все педагоги используют ИКТ в своей деятельности, и профессиональным достоинством является умение выстраивать эффективную педагогическую технологию, сочетая современные педагогические технологии и информационно-коммуникационные технологии (примеры см. в работе [6]). В перспективе развития образования детализированные представления о требующейся от педагогов ИКТ-компетентности будут претерпевать преобразования не только за счет прогресса в области технологических средств, но и за счет системного внедрения инновационных педагогических моделей, что отразится на содержании педагогических технологий; как пример перечень таких моделей обозначен в [22, с. 193].

\section{Литература}

1. Байденко В. И. Выявление состава компетенций выпускников вузов как необходимый этап проектирования ГОС ВПО нового поколения: методическое пособие. Москва, 2006. 72 с. Текст: непосредственный.

2. Витвицкая Л. А. Компетентностный подход в университетском образовании // Вестник Оренбургского государственного университета. 2011. № 11(130). С. 176-182. Текст: непосредственный.

3. Гурина Р. Как измерить профессиональную компетентность // Высшее образование в России. 2008. № 10. С. 82-89. Текст: непосредственный.

4. Дворовенко Н. Н. Математические закономерности в опыте анализа результатов обучения с использованием ДОТ некоторых категорий педагогов в модуле «ИКТ» программ курсов повышения квалификации // Вестник Бурятского государственного университета. Образование. Личность. Общество. 2016. № 2. С. 67-78. Текст: непосредственный.

5. Дворовенко Н. Н. Модель структуры ИКТ-компетентности педагогов // Информационно-коммуникационные технологии в образовательном процессе: от настоящего к будущему: материалы всероссийской научно-практической конференции (г. Кемерово, 22-23 марта 2016 г.): в 2 ч. / ред. кол.: Е. А. Пахомова, А. В. Чепкасов, Л. В. Чванова и др. Кемерово: Изд-во КРИПКиПРО, 2016. Ч. 1. С. 142-152. Текст: непосредственный.

6. Дворовенко Н. Н. Феномен интеграции информационно-коммуникационных технологий и современных педагогических технологий как вызов использованию традиционных подходов в новой образовательной среде // Информационнокоммуникационные технологии в образовательном процессе: от настоящего к будущему: материалы всероссийской научно-практической конференции (г. Кемерово, 22-23 марта 2016 г.): в 2 ч. / ред. кол.: Е. А. Пахомова, А. В. Чепкасов, Л. В. Чванова и др. Кемерово: Изд-во КРИПКиПРО, 2016. Ч. 1. С. 49-57. Текст: непосредственный.

7. Демин В. А. Профессиональная компетентность специалиста: понятие и виды // Стандарты и мониторинг в образовании. 2000. № 4. С. 34-42. Текст: непосредственный. 
8. Ильин Е. П. Умения и навыки: нерешенные вопросы // Вопросы психологии. 1986. № 2. С. 138-148. Текст: непосредственный.

9. Кротков Е. А., Носова Т. В. Диагностика // Энциклопедия эпистемологии и философии науки / под ред. И. Т. Касавина. Москва: «Канон+», 2009. С. 179-181. Текст: непосредственный.

10. Новиков А. М. Основания педагогики: пособие для авторов учебников и преподавателей педагогики. Москва: Эгвес, 2010. 208 с. Текст: непосредственный.

11. Сопряжение ФГОС и профессиональных стандартов: выявленные проблемы, возможные подходы, рекомендации по актуализации / С. А. Пилипенко, А. А. Жидков, Е. В. Караваева, А. В. Серова // Высшее образование в России. 2016. № 6(16). С. 5-15. Текст: непосредственный.

12. Равен Дж. Компетентность в современном обществе: выявление, развитие и реализация: пер. с англ. Москва: Когито-Центр, 2002. 396 с.; Raven J. (1984/1997). Competence in Modern Society: Its Identification, Development and Release. Unionville, New York: Royal Fireworks Press, 1984. URL: www.rfwp.com (First published in 1984 in London, England, by H. K. Lewis) (дата обращения: 05.03.2019). Текст: электронный.

13. Равен Дж. Педагогическое тестирование: проблемы, заблуждения, перспективы / пер. с англ. Ю. И. Турчаниновой и Э. Н. Гусинского. Москва: Когито-Центр, 1999. 142 с.; Raven J. The Tragic Illusion: Educational Testing. New York: Trillium Press; Oxford, England: Oxford Psychologists Press, 1991. 108 р. Текст: непосредственный.

14. Сенашенко В. С., Медникова Т. Б. Компетентностный подход в высшем образовании: миф и реальность // Высшее образование в России. 2014. № 5. С. 34-46. Текст: непосредственный.

15. Словарь иностранных слов / под ред. И. В. Лехина, С. М. Локшиной, Ф. Н. Петрова (гл. ред.) и Л. С. Шаумяна. Изд. 6-е, перераб. и доп. Москва: Сов. энциклопедия, 1964. 784 с. Текст: непосредственный.

16. Стариченко Б. Е. Профессиональный стандарт и ИКТ-компетенции педагога // Педагогическое образование в России. 2015. № 7. С. 6-15. Текст: непосредственный.

17. Третьякова Т. В. Педагогические измерения, их роль в оценивании качества образования // Вестник СВФУ. 2013. Т. 10, № 4. С. 116-120. Текст: непосредственный.

18. Уваров А. Ю. Структура ИКТ-компетентности учителей и требования к их подготовке: рекомендации ЮНЕСКО. Версия 2.0 // Информатика и образование. 2013. № 1(240). С. 26-40. Текст: непосредственный.

19. Философский словарь / под ред. И. Т. Фролова. Изд. 5-е. Москва: Изд-во политич. литературы, 1987. 590 с. Текст: непосредственный.

20. Шаронова С. А. Компетентностный подход и стандарты в образовании (сравнительный анализ стран ЕС и России) // Социс. 2008. № 1. С. 138-145. Текст: непосредственный.

21. Шилова О. Н., Лебедева М. Б. Как помочь учителю освоить современные технологии обучения: методическое пособие для преподавателей (тьюторов) системы РКЦММЦ проекта ИСО. Москва: ИНТУИТ.РУ, 2006. 132 с. Текст: непосредственный.

22. Шилова О. Н. Педагогические модели инновационного использования информационных технологий в образовании // Новые образовательные стратегии в современном информационном пространстве: сборник научных статей по материалам международной научной конференции (17-28 ноября 2014 г.). Санкт-Петербург: Изд-во РГПУ им. А. И. Герцена, 2015. С. 193. Текст: непосредственный. 
Н. Н. Дворовенко. Модель ИКТ-компетентности педагога: методология, структурные и содержательные составляющие, критерии оценивания

23. Шишов С. Е. Понятие компетенции в контексте качества образования // Стандарты и мониторинг в образовании. 1999. № 2. С. 30-34. Текст: непосредственный.

24. Stoof A., Martens R. L., Jeroen J. G. van Merrienboer. Что есть компетенция? Конструктивистский подход как выход из замешательства / пер. с англ. Е. Орел // Open University of the Netherlands. URL: http://www.ht.ru/cms/staff/426---------1 / (дата обращения: 05.03.2019). Текст: электронный.

Статья поступила в редакичю 26.01.2021; одобрена после рецензирования 25.01.2021; принята к публикации 09.04.2021.

\title{
MODEL OF INFORMATIONAL AND COMMUNICATIVE COMPETENCE OF EDUCATORS: METHODOLOGY, STRUCTURAL AND CONTENT COMPONENTS, EVALUATION CRITERIA
}

\author{
Nina N. Dvorovenko \\ Senior Lecturer, \\ Kuzbass Regional Institute of Advanced Training and Retraining of Educators \\ 23 Tukhachevskogo St., Kemerovo 650070, Russia \\ nina_dvorovenko@mail.ru
}

\begin{abstract}
The article discusses the structural and content components of the concept of informational and communicative competence of educators, including the concept of competence in aspects that have not been covered previously. To study the problematic of this issue we have analyzed the most important documents for educators. We have revealed the following problems in this field, such as the lack of information on the grounds for structuring, formalizing and universalizing the requirements for informational and communicative compe-tencies of educators, the lack of recommendations for lexical presentation of the formula-tions of competencies. The article gives specific proposals on a number of issues, and forms their methodological rationale; it also presents a list of key informational and communicative competencies and a model for assessing the informational and communicative competence of educators.

Keywords: competence; key informational and communicative competencies of educators; model of informational and communicative competence of educators; professional standard "Educator"; pedagogical technologies; methodology.
\end{abstract}

\section{For citation}

Dvorovenko N. N. Model of Informational and Communicative Competence of Educators: Methodology, Structural and Content Components, Evaluation Criteria. Education. Person. Society. 2021; 1: 17-39 (In Russ.).

The article was submitted 26.01.2021; approved after reviewing 25.01.2021; accepted for publication 09.04.2021. 